\title{
Leveraging graph-based semantic annotation for the identification of cause-effect relations
}

\author{
Susetyo Bagas Bhaskoro ${ }^{1}$, Inkreswari Retno Hardini ${ }^{2}$ \\ ${ }^{1}$ Department of Manufacturing Automation and Mechatronics Engineering Technology, \\ Politeknik Manufaktur Bandung, Indonesia \\ ${ }^{2}$ School of Electrical Engineering and Informatics, Institut Teknologi Bandung, Indonesia
}

\begin{tabular}{l} 
Article Info \\
\hline Article history: \\
Received Nov 15, 2019 \\
Revised Feb 21, 2020 \\
Accepted Mar 1, 2020 \\
\hline
\end{tabular}

Keywords:

Causal

Medical element annotation

Paragraph annotation

Phrase annotation

Semantic annotation

\begin{abstract}
This research is related to language article in Indonesia that discuss about causality relationship research used as public health surveillance information monitoring system. Utilization of this research is suitability of feature selection, phrase annotation, paragraph annotation, medical element annotation and graph-based semantic annotation. Evaluation of system performance is done by intrinsic approach using the naive bayes multinomial method. The results obtained sequentially for recall, precision and f-measure are $0.924,0.905$, and 0.910 .
\end{abstract}

Copyright (C) 2020 Institute of Advanced Engineering and Science. All rights reserved.

\section{Corresponding Author:}

Susetyo Bagas Bhaskoro,

Department of Manufacturing Automation and Mechatronics Engineering Technology,

Politeknik Manufaktur Bandung,

Kanayakan Street, No. 21, Bandung, Indonesia.

Email: bagas@ polman-bandung.ac.id

\section{INTRODUCTION}

Research on natural language processing is increasing because it is influenced by the availability of information that always increases. One example is natural language processing in the health domain whose source of information is not only derived from the patient's medical record, but through community writing participation shared using internet media [1]. Not a few practitioners, communities and even health service units seek medical information and utilize information on the internet for certain purposes. One of the characteristics of information seeking in the health domain is that the search for health information will end when information on cause and effect has been found that discusses the root causes of a medical condition.

$$
f(x, y)=(x) \rightarrow(y) ; \text { or } f(x, y)=i f(x) \text { then }(y)
$$

Meanwhile, having a large collection of medical information from various sources brings challenges for practitioners and the public to find the information they need in a fast time. Getting new knowledge from medical articles automatically becomes a separate problem because the sentence usually written on medical articles has the characteristics of multiple sentences [2], namely a long article that usually has several paragraphs, the explanation consists of background then presents the problem and provides solutions to the core part of the article and ends with conclusions or messages that are considered important [3, 4]. There is a possibility that in an article, the position of the causal relationship pattern allows to be in a different paragraph, meaning the sentence because it can be written at the beginning of paragraphs and sentences due to being explained at the end of the paragraph, and vice versa. 


$$
\begin{array}{r}
f(x, y, z)=x \text { is the potential for development } y, \\
x \text { cause } z, \text { and } y \text { is the main cause of } z
\end{array}
$$

The purpose of this research is to optimize the use of annotations to do a summary of an online medical article in which it is able to display the meaning of cause and meaning as a result of which the two meanings have a mutually explaining relationship. Overall, this study aims to contribute as follows: (a) proposed phrase annotations used to identify implicit meanings in a sentence; (b) proposed paragraph annotations are used to carry out the core classification of the discussion in each paragraph in the medical article; (c) proposed annotations of medical elements are used to transform natural language into medical annotations; (d) proposed graph-based semantic annotations are used to identify cause-effect relationships through a template-based.

\section{RESEARCH METHODOLOGY}

The method used as a reference is Atkinson's research [5]. The difference with the current research lies in the summary section of the text, the transformation of medical elements, semantic annotations and paragraph annotations shown in Figure 1 (blocks given dark background colors). The current research is using an online medical article dataset for public health surveillance. The aim is to display information on causes and consequences, as well as the mitigation process from the occurrence of these health cases. The challenge in the current research is to determine the medical elements that match the characteristics of the text in Indonesian medical articles.

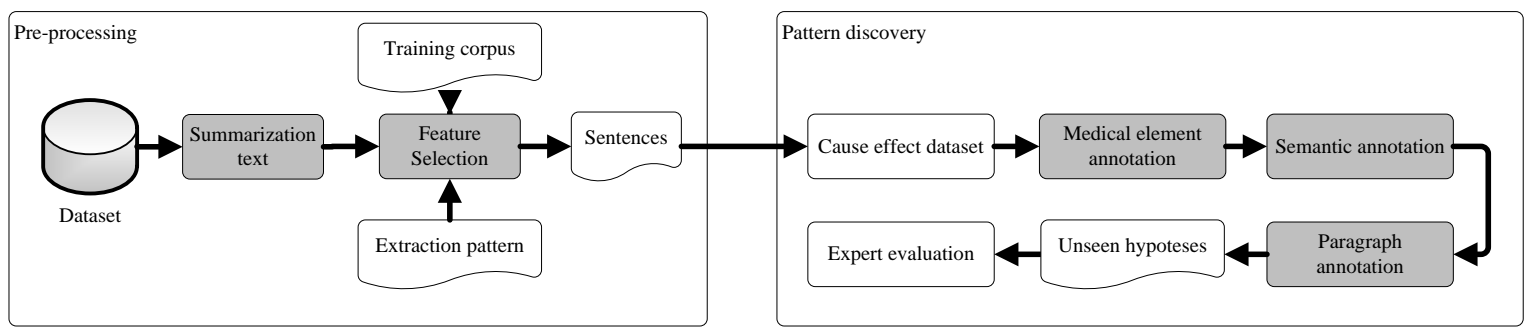

Figure 1. Process approach for the identification of causal relationship in multiple sentences

\subsection{Summary of extractive text}

The principle of using text summaries in the current research is to complete the stages of feature selection needed by Atkinson [5], in addition summary techniques are used to narrow the problem search space and the characteristic used in the text summary phase [6].

\subsection{Transforming natural languages into medical element annotations}

Annotation is a technique used to give notes to each sentence. This solution is used to find important sentences discussed in a medical text. The fact is that the results of annotations actually have a lot of connection with other annotations that form new meanings [7]. Here is an annotation comparison proposed by several other researchers. Atkinson [5] proposed annotation are substance, effect, symptom, disease, and body part. Mihăilă [7] proposed annotation are drug, physical stimulation, symptom, inhibition, and diagnosis. Byrd [8] utilizing the information occurs on Twitter for public health surveillance with annotations used are sentiment analysis and geocoding. Liang $\mathrm{Wu}$ [9] using twitter to find out information about the reactions of drugs consumed with the annotations used are drug name, brand name, prescribe for, effect. Yanging Ji [10] utilizing health articles by using annotations drug name, ICD Code, and symptom. Yepes [11] used annotations for surveillance problems. The proposed annotations are disease, symptoms, pharmacological and location.

The obstacle of the several annotations that have been proposed is that it has not been able to display a dependency relationship that explains the meaning of cause and effect, therefore in the current study the semantic annotation is proposed to relate the meaning of each annotation that has a connection pattern with other annotations according to medical information needs. Table 1 is the proposal to develop natural language into the LPPAJSFPEPnGOD medical element by considering the needs of the dataset taken from online articles, namely handling in the form of statements from resource persons, facilities, and recovery that have been carried out as indicators of mitigation. 
Table 1. Proposed LPpAJSFPePnGOD for medical element annotations

\begin{tabular}{|c|c|}
\hline Medical Entities & Description \\
\hline $\begin{array}{l}\text { LOKAS I ( L ) } \\
\text { In English } \\
\text { LOCATION }\end{array}$ & $\begin{array}{l}\text { Used to extract location and place names about events or events being discussed } \\
\text { The rule is Location }(x, y) \rightarrow \text { probability of location. }\end{array}$ \\
\hline $\begin{array}{l}\text { POPULASI } \\
\text { PENYAKIT (Pp) } \\
\text { In English } \\
\text { DISEASE } \\
\text { POPULATION }\end{array}$ & $\begin{array}{l}\text { Used to perform extraction issues and problems of the disease. Get the problem issues with the approach of } \\
\text { the method of biological named entity recognition. } \\
\text { The rule is Disease population ( } x, y) \rightarrow \text { biological probability named entity } \\
\text { recognition (biological NER). }\end{array}$ \\
\hline $\begin{array}{l}\text { AKIBAT (A) } \\
\text { In English } \\
\text { EFFECT }\end{array}$ & $\begin{array}{l}\text { Used to perform the extraction impact by the subject as specific disease populations. } \\
\text { The rule is Effect }(x, y) \rightarrow \text { disease_population }(x) \text {, location }(y) \text {. }\end{array}$ \\
\hline $\begin{array}{l}\text { JUMLAH } \\
\text { KEJADIAN } \quad(\mathrm{J}) \\
\text { In English } \\
\text { SUM OF EVENTS }\end{array}$ & $\begin{array}{l}\text { Used to perform the extraction of statistical count in numeral from the population of certain diseases. } \\
\text { The rule is Sum_of_events }(x, y) \rightarrow \text { effect }(x, y) \text {. }\end{array}$ \\
\hline $\begin{array}{l}\text { SEBAB }(S) \\
\text { In English } \\
\text { CAUSE }\end{array}$ & $\begin{array}{l}\text { Used to perform the extraction of the main causes. The method for obtaining a cause is to calculate the word } \\
\text { emergence statistics on online articles and classification of certain disease populations. } \\
\text { The rules are Cause_1 }(x, y) \rightarrow \text { disease_population }(x, y) ; \text { Cause_2 }(x, y) \rightarrow \\
\text { sum_of_events }(x, y) ; \text { Cause_3 }(x, y) \rightarrow \text { sum_of_events }(x), \text { location }(y) \text {. }\end{array}$ \\
\hline $\begin{array}{l}\text { FASILITAS } \quad(\mathrm{F}) \\
\text { In English } \\
\text { FACILITY }\end{array}$ & $\begin{array}{l}\text { Used to name extraction institutions that provide treatment based on the consequences of certain disease } \\
\text { populations. } \\
\text { The rules are Facility_1 }(\mathrm{x}, \mathrm{y}) \rightarrow \text { disease_population }(\mathrm{x}) \text {, sum_of_events }(\mathrm{y}) \text {; } \\
\text { Facility_2 }(\mathrm{x}, \mathrm{y}) \rightarrow \text { effect }(\mathrm{x}, \mathrm{y}) \text {; Facility_3 (x, y) } \rightarrow \text { cause_1 }(\mathrm{x}, \mathrm{y}) \text {. }\end{array}$ \\
\hline $\begin{array}{l}\text { PEMULIHAN ( } \mathrm{Pe}) \\
\text { In English } \\
\text { RECOVERY }\end{array}$ & $\begin{array}{l}\text { Used to solution extraction prepared and carried out from facilities in certain locations. } \\
\text { The rules are Restitution_1 (x, y) } \rightarrow \text { facility_1 (x, y); Restitution_2 (x, y) } \\
\rightarrow \text { facility }(x), \text { location }(y) \text {. }\end{array}$ \\
\hline $\begin{array}{l}\text { GEJALA (G) } \\
\text { In English } \\
\text { SYMPTOMS }\end{array}$ & $\begin{array}{l}\text { Used to extraction part of the body are diseased or in pain. } \\
\text { The rules are Symptoms }(x, y) \rightarrow \text { disease_population }(x, y) ; \text { Symptoms }(x, y) \rightarrow \\
\text { disease_population }(x, y)\end{array}$ \\
\hline $\begin{array}{l}\text { OBAT (O) } \\
\text { In English } \\
\text { DRUGS }\end{array}$ & $\begin{array}{l}\text { Used to information extraction drug or vaccine, as one method of recovery. } \\
\text { The rule is Drugs }(x, y) \rightarrow \text { cause_1 }(x), r e c o v e r y(y)\end{array}$ \\
\hline $\begin{array}{l}\text { DIAGNOSA (D) } \\
\text { In English } \\
\text { DIAGNOSE }\end{array}$ & $\begin{array}{l}\text { Used to extraction of information related to medical statement about the disease. } \\
\text { The rule is diagnosis }(x, y) \rightarrow \text { disease_population }(x), \text { symptoms }(y)\end{array}$ \\
\hline
\end{tabular}

\subsection{Paragraph annotation}

Paragraph annotations are needed because the important messages conveyed in online medical articles are in unpredictable paragraphs or each paragraph discusses the different core stories. Therefore the main task of paragraph annotations is to produce the essence of word categories on medical content consisting of core paragraphs, supporting paragraphs and conclusion paragraphs. List the paragraph position annotations as found in Table 2. If the core story of each paragraph has been obtained, then the pattern of the graph pair from the paragraph classification can be determined based on the rules of pattern in Figure 2 .

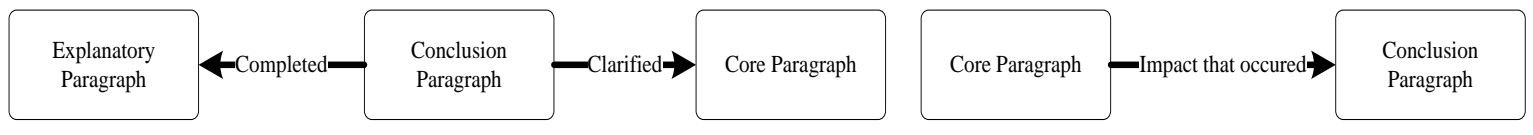

Figure 2. Connection of meaning based on annotations of paragraph positions 
Table 2. Proposed paragraph annotation

\begin{tabular}{|c|c|}
\hline Paragraph Annotation & Characteristics \\
\hline Core Paragraph & $\begin{array}{l}\text { Sentences that have frequency of occurrence more than the other sentences and describe } \\
\text { the event being discussed; The core sentence in it has a meaningful effect; The sentence describes } \\
\text { the fact of an event discussed. Elements related to the core paragraph as follows: Amount in numbers: } \\
\text { the number of events, evidence of the incident; effects; pharmacy; diagnosis; Signs in the body related } \\
\text { to the symptoms. Techniques for use calculating the frequency of the number of words and do a ranking } \\
\text { based on a threshold value of the article. }\end{array}$ \\
\hline \multirow[t]{2}{*}{ Explanatory Paragraph } & $\begin{array}{l}\text { Sentences that are identical to information on the cause of an event; Sentence describing } \\
\text { the subject discussed in the article; Sentence that defines the name of the disease that are discussed in } \\
\text { this article; Sentence that describes the description of the place. The related of elements to explanatory } \\
\text { paragraphs are: Location: country, city, district, address; Disease; cause; subject: person, object; } \\
\text { Comparison sentence. The technique for using is calculate the occurrences frequency of words number } \\
\text { and rank based on the threshold value of the article: }\end{array}$ \\
\hline & $\begin{array}{l}\text { Loop article, sum of [] } \\
\text { \{element_paragraph_core, } \\
\text { position_paragraph_core = n } \\
\mathrm{n}=\mathrm{n}+1\} \\
\text { End loop }\end{array}$ \\
\hline Conclusion Paragraph & $\begin{array}{l}\text { Sentence that describes the mitigation of the ongoing activity; The sentence that defines } \\
\text { the facilities discussed in the article. The related of Elements to the conclusion paragraph are: } \\
\text { Mitigation; Facilities provided. The technique for using is calculate the occurrences frequency of words } \\
\text { number and rank based on the threshold value of the article: }\end{array}$ \\
\hline
\end{tabular}

\subsection{Feature selection}

Selection of features tailored to the characteristics of the text in complex medical articles and the meaning of medical sentences. Analysis of the pre-processing features used in medical articles as in the current research is better not to use this pre-processing stage, compared to using it because the results are ambiguous [12]. Figure 3 is the pre-processing stage in question.

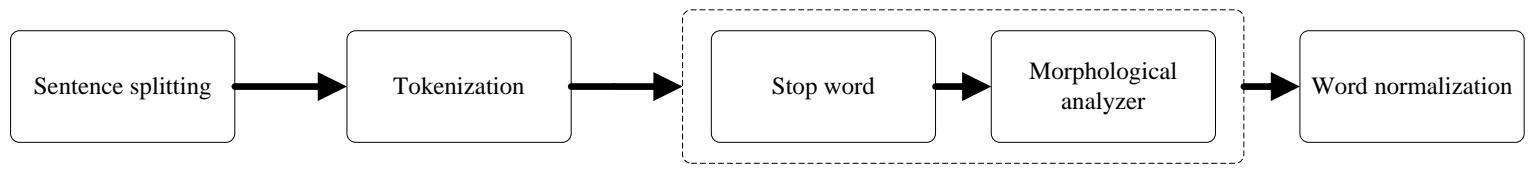

Figure 3. Stages of pre-processing

The first stage is sentence splitting, which is to separate sentences until the delimiter '.' But not all delimiter signs are the final marker of a sentence. For example, like 'dr.' The word is not the end of a sentence, but a profession title. The second stage is tokenization, which is to separate each word from a sentence. Examples of problems such as the sentence <rumah sakit in English is hospital>. The sentence is one term not $<$ home $>$ and $\langle$ sick $>$ or $\langle$ care $\rangle$, as well as $\langle$ Ministry of Health $\rangle$. The sentence is one term not $<$ ministry $>$ and $<$ health $>$.

The last step is the morphological analyzer, which converts a word into a basic word. An example is <immunized>. The word has a suffix in bahasa language (di-), (sasi-) and the basic word is <immune>. Immunized has the meaning of being given a vaccine for the immune system, while the immune system is the immune system. The analysis of the other feature selection is $n$-gram as seen in the following equation:

$\mathrm{P}\left(\mathrm{k}_{1}, \mathrm{k}_{2}, \ldots, \mathrm{k}_{\mathrm{n}}\right)=\mathrm{P}\left(\mathrm{k}_{1}\right) \mathrm{P}\left(\mathrm{k}_{2} \mid \mathrm{k}_{1}\right) \ldots \mathrm{P}\left(\mathrm{k}_{\mathrm{n}} \mid \mathrm{k}_{1} \ldots \mathrm{k}_{\mathrm{n}-1}\right)$ 
a positive class label if in the sentence $<$ verb $>$ and $<$ noun $>$ have a positive meaning, while labeling a negative class if in that sentence $<$ verb $>$ and $<$ noun $>$ have negative meanings. The experiment conducted a comparison of several classification techniques [17], namely (a) testing using lexical; (b) using the naïve bayes method; and (c) using the SVM method. Table 3 is the result of a comparison of explicit and implicit data modeling analysis to identify patterns of causal relationships with other researchers, as follows:

Table 3. Comparison of testing identification of cause relations

\begin{tabular}{|c|c|c|}
\hline Researcher & Feature proposed & Accuracy \\
\hline Ittoo [18] & <verb> Wikipedia + Lexical. & 0.650 \\
\hline Rink [19] & Word+PoS+Parse graphs + word+PoS+Parse+Stem & 0.381 \\
\hline Riaz [3] & Tagging Verb + Noun & 0.807 \\
\hline The proposed & Tagging Verb + Noun + Tagging phrase + LB & 0.650 \\
\hline model (current & Tagging Verb + Noun + Tagging phrase + NB & 0.660 \\
\hline study) & Tagging Verb + Noun + Tagging phrase + SVM & 0.890 \\
\hline
\end{tabular}

\subsection{Multi-feature selection}

This test uses a summary technique to narrow down the problem search space, then combines with the semantic pattern modeling method and the proposed annotation to find important sentences that have a meaningful cause-effect relationship. The following is the pseudo code for the feature selection, weighting and n-gram used in the summary system. The next test is to combine summary + annotation of medical elements + phrase tagging + opinion analysis. The aim is to get a summary that is more in line with the information search needs of the medical domain and has a pattern of causal relationships. Because this research is a subjective classifier, the learning model must be adjusted based on the individual preferences of the labeler or an expert and the label results may vary. Therefore, research activities explore features by means of classification. The following is one example of a medical article taken from online media and used as an experimental dataset in the current research. In this study using a dataset of 500 medical articles online and when extracted it had sentences of 10,176 sentences. The method used as a comparison for the classification of summaries + annotations of medical elements + phrase tagging + analysis of opinion is naïve Bayes.

The current research is able to answer from previous studies when the output of more than one entity then the meaning becomes ambiguous as mentioned in Khoo's research [20-22] and Park [23]. This study even though the results of medical elements obtained more than one entity, then the technique is by doing a ranking to get the medical element into one entity using the calculation of the frequency of occurrence of words. The results obtained using a summary approach + annotation of medical elements + phrase tagging + opinion analysis to find important information in medical text articles that have causal meanings as found in Table 4.

Pseudo code combination of feature selection, n-Best and weighting

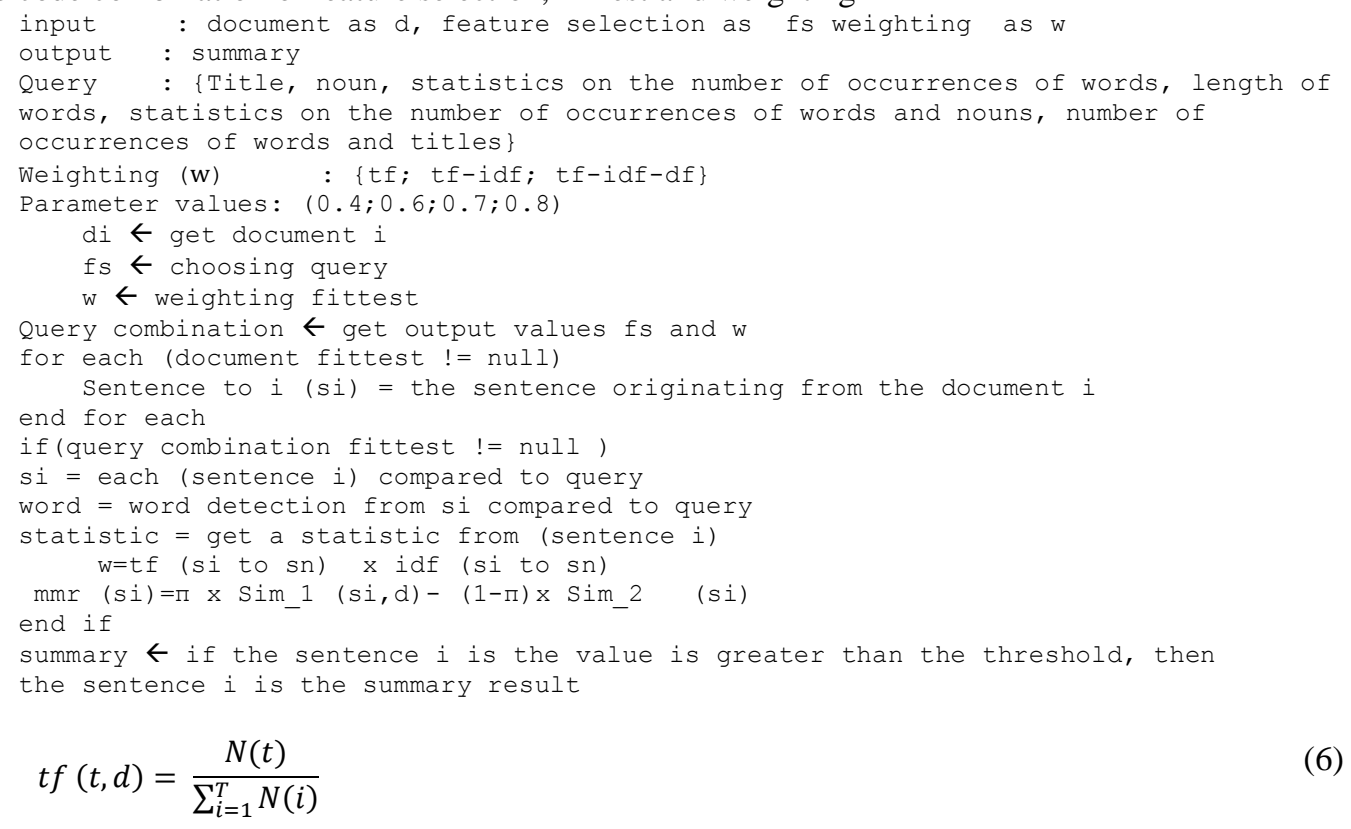


Table 4. Comparison for testing the identification of cause-effect relations

\begin{tabular}{|c|c|c|c|c|}
\hline Researcher & Features & Recall & Precision & f1 \\
\hline Riaz [24] & Tagging Verb + Noun & 0.807 & - & - \\
\hline Mihăilǎ [7] & $\begin{array}{l}\text { Biocause: drug, physical stimulation, symptom, } \\
\text { inhibition, dan diagnosis. } \\
\text { Proposed annotations are disease symptoms, }\end{array}$ & - & - & 0.873 \\
\hline Yepes [11] & $\begin{array}{l}\text { pharmacological and location. disease, symptoms, } \\
\text { pharmacological dan location. }\end{array}$ & 0.214 & 0.938 & - \\
\hline $\begin{array}{l}\text { The proposed } \\
\text { model (current } \\
\text { study) }\end{array}$ & $\begin{array}{l}\text { Summary + annotations medical elements + phrase } \\
\text { tagging + opinion analysis }\end{array}$ & 0.924 & 0.905 & 0.910 \\
\hline
\end{tabular}

\subsection{Dependency relation}

At this stage the discussion adds a paragraph annotation and semantic annotation approach to display new knowledge, so that readers can easily understand the summary results in a medical text article that displays important information and has a meaningful cause-effect relationship [25]. The technique for dependency relations is a combination of rule-based and statistical based. Rule-based techniques are used when the annotation resulting from the classification of paragraph sentences in medical articles must be paired with the classification of other paragraph sentences as shown in Figure 2. Interrelation of meaning based on paragraph position annotations and Figure 4. The following is a rule-based pseudo code.

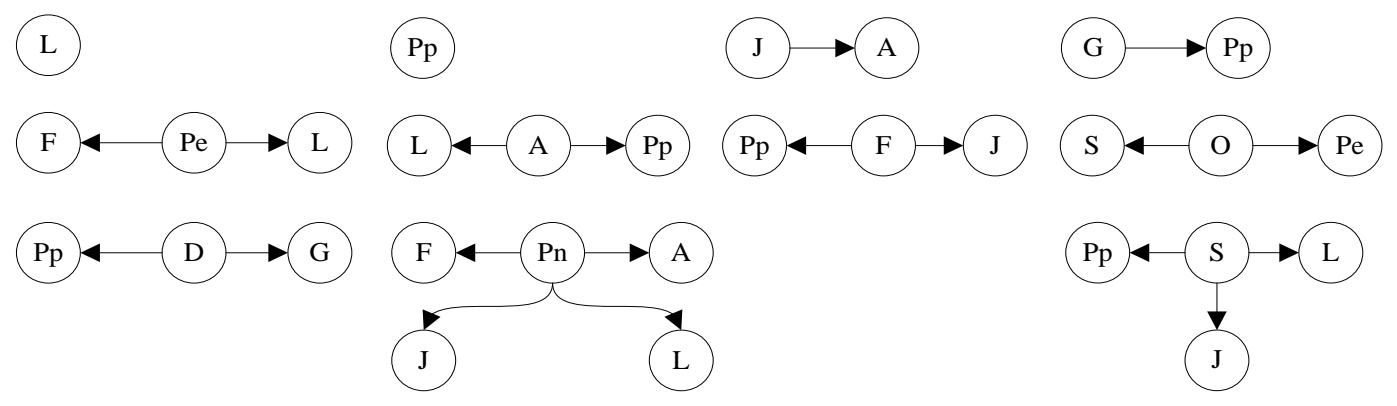

Figure 4. Graph-based of semantic annotation

Pseudo code-based word linkage

Cause pattern identification:

Cause entity $==$ [Disease population]

The word position is in the explanatory paragraph and core paragraph

Cause is words that have confidence (association) $=0.2$ from the ratio of all words (in the

form of [noun] + [noun]).

Words positions there is in the explanatory paragraph and core paragraph.

Effect pattern identification

effect entity $=$ [words has a negative meaning]

effect entity = words has a negative meaning + nominal + medical element [sum of events]

effect entity $=$ words has a negative meaning + medical meaning [facilities]

effect entity = words has a negative meaning and confidence value (association) = 0.2

Words positions there is in the explanatory paragraph and core paragraph.

Machine learning-based are used when conducting annotation classification of medical elements and paragraph annotations. The following is a statistical pseudo code:

Pseudo code word-based statistical connectivity

Training data

Insert two sentences that have a relationship and each other's has a class

classification results

1. sentences $A=$ [cause]

2. sentences $B=$ [facility]

3. sentences $C=$ [effect]

4. sentences $D=$ [sum of event]

5. sentences $E=$ [responsible person]

6. sentences $F=$ [population disease]

7. sentences $G=$ [effect]

8. sentences $A$ and sentences $G=$ [causal] 
Pseudo code word-based statistical connectivity

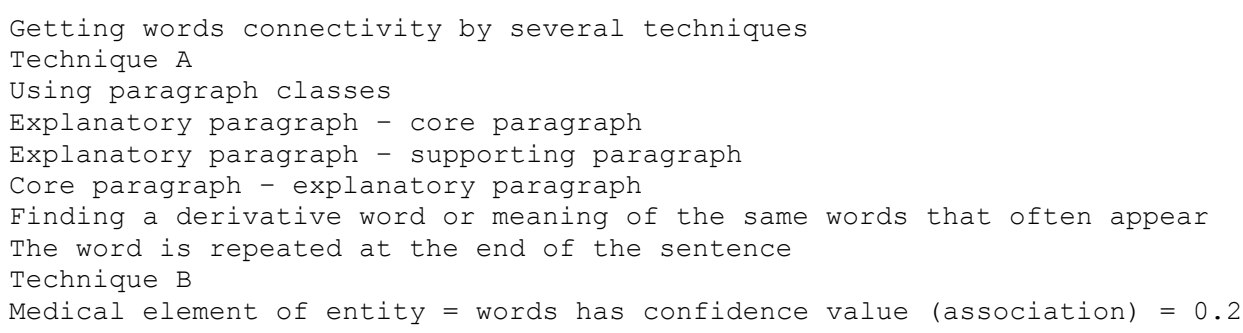

The technique used in the current research is to build new knowledge by combining rule-based and statistical-based dependency relations to display summaries of important information aided by the formation of new knowledge patterns as shown in Table 5.

Table 5. Knowledge discovery

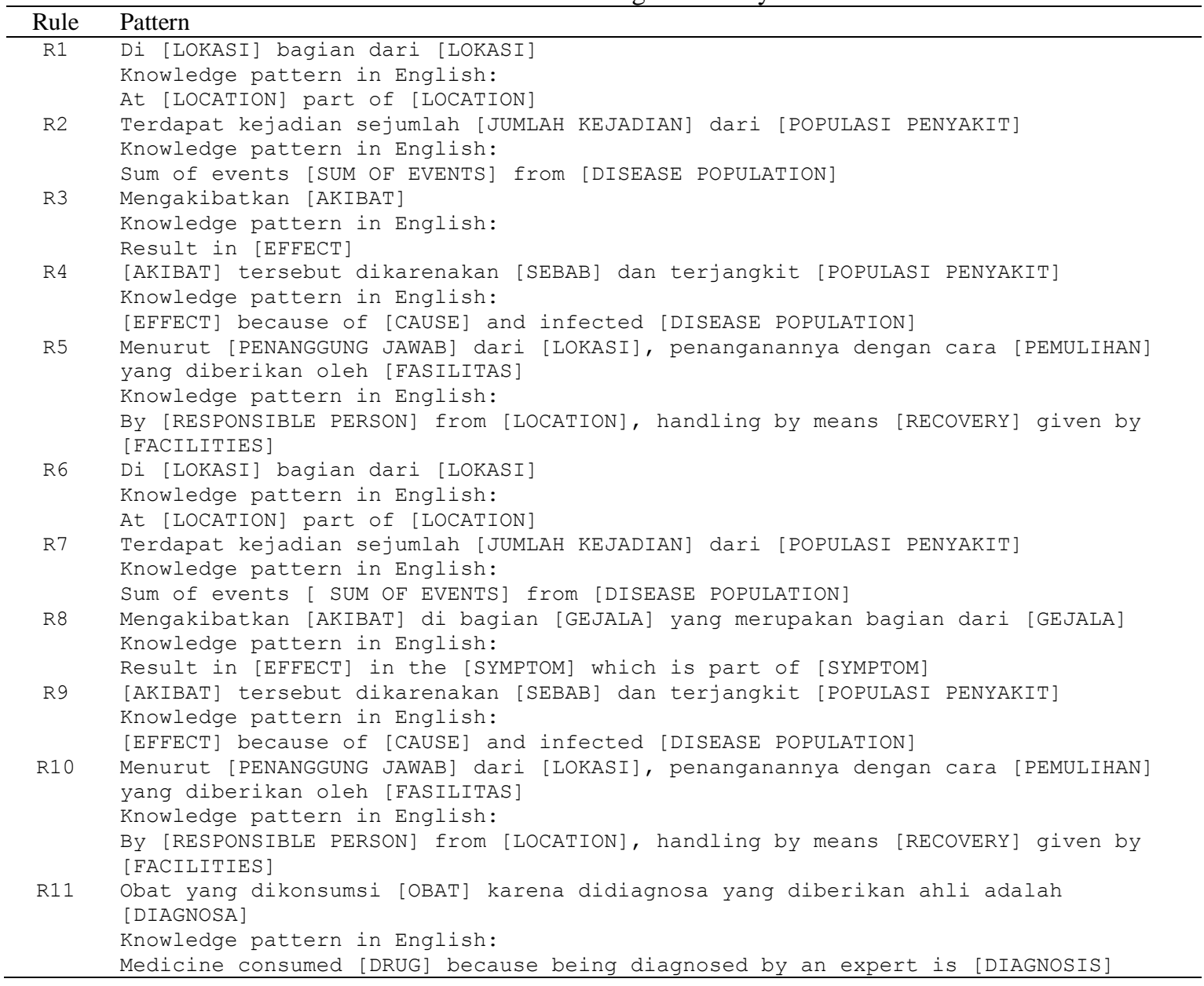

The output from the mapping of new knowledge formation patterns with the results of the classification of paragraph annotations in summary form looks like the following. In this research take an example of data testing using online articles [26]:

Di <Desa Sigedong Kabupaten Temanggung> terdapat seorang meninggal dunia karena Diare. Sebagai penanggulangannya Dinkes Temanggung telah mendirikan Posko dan melakukan sosialisasi untuk menerapkan hidup bersih dan sehat.

In English:

In Sigedong Village, Temanggung Regency, one person died of Diarrhea. As a response, the Temanggung Health Office has established a Command Post and conducted socialization to implement a clean and healthy life. 
The testing scenarios carried out for the stages of dependency relations are more focused on extrinsic evaluation which is divided into two categories, namely in Table 6 which is used for testing based on the suitability of the summary results, appropriate summary outputs, and inappropriate outputs. Remarks for Table 6: (a) summary by an expert; (b) summary by the system; (c) the appropriate output (d) the output is not appropriate. Based on Table 6 seen in point (a), an expert determines the output that should be generated by the system, then in point (b) is the output generated by the system using a combination of summary features + annotations of medical elements + phrase tagging + opinion analysis. In point (c) is a comparison between the output determined by an expert, with the output produced by the system. Pattern (d) is a non-matching comparison of output between points (a) and points (b). The results of the average success of the system to produce output in accordance with an expert's decision are 0.857 . Figure 5 is a comparison of the performance output produced by the system with a decision previously made by an expert. The results obtained on the system are said to be good when approaching the value of ' 1 ', meaning that the output on the system has a degree of similarity to the decisions made by an expert.

Meanwhile, Table 7 is used for evaluating an expert's evaluation of the outputs generated from the system integration semantic template method with a health surveillance system. Based on Table 7 the results obtained from extrinsic evaluation are 0.720 with the decision to agree. The assessment given by an expert into a system between 0-100. The decision agreed to illustrate that the summary method + annotation of medical elements + phrase tagging + opinion analysis, the system is able to produce results that resemble the way an expert does inference.

Table 6. Testing annotation fitness

\begin{tabular}{|c|c|c|c|c|c|c|c|c|c|c|c|c|c|c|c|c|c|c|c|c|}
\hline \multirow{2}{*}{ \# } & \multicolumn{4}{|c|}{ E1 } & \multicolumn{4}{|c|}{ E2 } & \multicolumn{4}{|c|}{ E3 } & \multicolumn{4}{|c|}{ E4 } & \multicolumn{4}{|c|}{ E5 } \\
\hline & $\mathrm{a}$ & $\mathrm{b}$ & $\mathrm{C}$ & $\mathrm{d}$ & $\mathrm{a}$ & $\mathrm{b}$ & C & $\mathrm{d}$ & $\mathrm{a}$ & $\mathrm{b}$ & $\mathrm{C}$ & $d$ & a & $\mathrm{b}$ & C & $d$ & $\mathrm{a}$ & $\mathrm{b}$ & $\mathrm{C}$ & $d$ \\
\hline 1 & 6 & 13 & 5 & 1 & 8 & 13 & 8 & 0 & 7 & 13 & 6 & 1 & 5 & 13 & 5 & 0 & 9 & 13 & 9 & 0 \\
\hline 2 & 7 & 7 & 4 & 3 & 6 & 7 & 4 & 2 & 7 & 7 & 4 & 3 & 6 & 7 & 5 & 1 & 7 & 7 & 7 & 0 \\
\hline 3 & 9 & 21 & 8 & 1 & 11 & 21 & 10 & 1 & 11 & 21 & 8 & 3 & 12 & 21 & 12 & 0 & 11 & 21 & 10 & 1 \\
\hline 4 & 6 & 11 & 6 & 0 & 8 & 11 & 7 & 1 & 7 & 11 & 6 & 1 & 9 & 11 & 9 & 0 & 7 & 11 & 7 & 0 \\
\hline 5 & 6 & 14 & 6 & 0 & 8 & 14 & 7 & 1 & 5 & 14 & 4 & 1 & 10 & 14 & 10 & 0 & 8 & 14 & 8 & 0 \\
\hline 6 & 5 & 11 & 5 & 0 & 6 & 11 & 6 & 0 & 7 & 11 & 6 & 1 & 8 & 11 & 5 & 3 & 7 & 11 & 7 & 0 \\
\hline 7 & 11 & 8 & 8 & 3 & 8 & 8 & 8 & 0 & 8 & 8 & 5 & 3 & 11 & 8 & 8 & 3 & 8 & 8 & 8 & 0 \\
\hline 8 & 4 & 5 & 3 & 1 & 4 & 5 & 2 & 2 & 5 & 5 & 4 & 1 & 4 & 5 & 3 & 1 & 4 & 5 & 4 & 0 \\
\hline 9 & 9 & 10 & 7 & 2 & 8 & 10 & 6 & 2 & 9 & 10 & 8 & 1 & 9 & 10 & 7 & 2 & 9 & 10 & 8 & 1 \\
\hline 10 & 5 & 7 & 4 & 1 & 6 & 7 & 5 & 1 & 6 & 7 & 6 & 0 & 5 & 7 & 4 & 1 & 5 & 7 & 4 & 1 \\
\hline
\end{tabular}

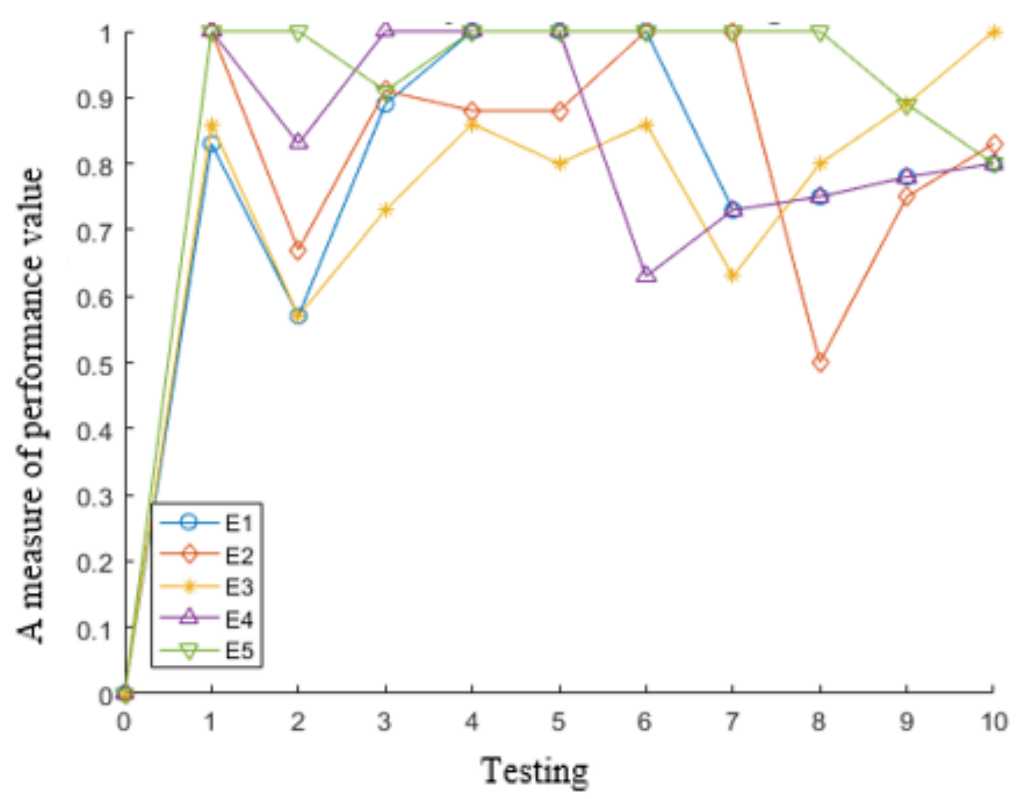

Figure 5. Comparison of system performance output with decisions of an expert on a system 
Table 7. Assessment of an expert assessment

\begin{tabular}{cccccc}
\hline Testing & E1 & E2 & E3 & E4 & E5 \\
\hline 1 & 0.80 & 0.70 & 0.70 & 0.80 & 0.70 \\
2 & 0.80 & 0.70 & 0.80 & 0.80 & 0.80 \\
3 & 0.70 & 0.80 & 0.80 & 0.70 & 0.70 \\
4 & 0.70 & 0.80 & 0.80 & 0.70 & 0.80 \\
5 & 0.80 & 0.80 & 0.80 & 0.70 & 0.70 \\
6 & 0.70 & 0.70 & 0.80 & 0.70 & 0.70 \\
7 & 0.70 & 0.70 & 0.70 & 0.70 & 0.70 \\
8 & 0.80 & 0.80 & 0.80 & 0.80 & 0.70 \\
9 & 0.80 & 0.80 & 0.80 & 0.80 & 0.80 \\
10 & 0.70 & 0.80 & 0.80 & 0.80 & 0.80 \\
\hline
\end{tabular}

\section{CONCLUSION}

Generated semantic template method that has been successfully implemented on health domain is public health surveillance system. During implementation, there are several proposals have been generated, i.e. natural language transformation into medical element annotation (LPpAJSFPePnGOD) to identify causal relationship pattern, paragraph annotation pattern to classify sentence position on medical article paragraph and build a semantic relationship pattern for semantic annotation.

\section{REFERENCES}

[1] S. Akbar, L. Slaughter, and Ø. Nytroø, "Collecting health related text from patient health writings," in The 2nd International Conference on Computer and Automation Engineering, vol. 1, pp. 15-19, 2010.

[2] C. Hidey and K. Mckeown, "Identifying Causal Relations Using Parallel Wikipedia Articles," in Proceedings of the 54th Annual Meeting of the Association for Computational Linguistics, pp. 1424-1433, 2016.

[3] M. Riaz and R. Girju, "Recognizing Causality in Verb-Noun Pairs via Noun and Verb Semantics," in EACL 2014 Workshop on Computational Approaches to Causality in Language (CAtoCL), no. 1, pp. 48-57, 2014.

[4] K. Hanawa, A. Sasaki, N. Okazaki, and K. Inui, "A Crowdsourcing Approach for Annotating Causal Relation Instances in Wikipedia," in The 31st Pacific Asia Conference on Language, Information and Computation, pp. 336-345, 2016.

[5] J. Atkinson and A. Rivas, "Discovering novel causal patterns from biomedical natural-language texts using Bayesian nets," IEEE Trans. Inf. Technol. Biomed, vol. 12, no. 6, pp. 714-722, 2008.

[6] S. H. S. Susetyo Bagas Bhaskoro, Saiful Akbar, "Enhancing Performance in Medical Articles Summarization with Multi-feature Selection," International Journal of Electrical and Computer Engineering (IJECE), vol. 8, no. 4, pp. 2299-2309, 2018.

[7] C. Mihăilă, T. Ohta, S. Pyysalo, and S. Ananiadou, "BioCause: Annotating and analysing causality in the biomedical domain," BMC Bioinformatics, vol. 14, no. 2, pp. 1-18, 2013.

[8] K. Byrd, A. Mansurov, and O. Baysal, "Mining Twitter data for influenza detection and surveillance," Proc. Int. Work. Softw. Eng. Healthc. Syst. - SEHS '16, pp. 43-49, 2016.

[9] L. Wu, T.-S. Moh, and N. Khuri, "Twitter opinion mining for adverse drug reactions," 2015 IEEE Int. Conf. Big Data (Big Data), pp. 1570-1574, 2015.

[10] Y. Ji et al., "A potential causal association mining algorithm for screening adverse drug reactions in postmarketing surveillance," IEEE Trans. Inf. Technol. Biomed, vol. 15, no. 3, pp. 428-437, 2011.

[11] A. J. Yepes, A. MacKinlay, and B. Han, "Investigating Public Health Surveillance using Twitter," Proc. 2015 Work. Biomed. Nat. Lang. Process. (BioNLP 2015), Beijing, China, July 30, 2015, no. BioNLP, pp. 164-170, 2015.

[12] S. B. Bhaskoro, S. Akbar, and S. H. Supangkat, "Identification of Causal Pattern using Opinion Analysis in Indonesian Medical Texts," in 2015 International Conference on Information Technology Systems and Innovation (ICITSI), pp. 1-7, 2015.

[13] S.-L. Hsieh, W.-Y. Chang, C.-H. Chen, and Y.-C. Weng, "Semantic similarity measures in the biomedical domain by leveraging a web search engine.," IEEE J. Biomed. Heal. informatics, vol. 17, no. 4, pp. 853-861, 2013.

[14] N. Mostafazadeh, A. Grealish, N. Chambers, J. Allen, and L. Vanderwende, "CaTeRS: Causal and Temporal Relation Scheme for Semantic Annotation of Event Structures," Proceedings of the 4th Workshop on Events: Definition, Detection, Coreference, and Representation, pp. 51-61, 2016.

[15] A. Kogilavani and P. Balasubramanie, "Sentence Annotation based Enhanced Semantic Summary Generation from Multiple Documents," Journal, Am. Sci. Appl. Publ. Sci., vol. 9, no. 7, pp. 1063-1070, 2012.

[16] K. Okoye, A. R. H. Tawil, U. Naeem, R. Bashroush, and E. Lamine, "A semantic rule-based approach supported by process mining for personalised adaptive learning," Procedia Comput. Sci, vol. 37, pp. 203-210, 2014.

[17] S. B. Bhaskoro, S. Akbar, and S. H. Supangkat, "Extracting Important Sentences for Public Health Surveillance Information from Indonesian Medical Articles," in The International Conference on ICT for Smart Society (ICISS), pp. 1-7, 2017.

[18] A. Ittoo and G. Bouma, "Extracting Explicit and Implicit Causal Relations from sparse, Domains-Specific Texts," in NLDB'11 Proceedings of the 16th international conference on Natural language processing and information systems, pp. 52-63, 2011. 
[19] B. Rink, C. A. Bejan, and S. Harabagiu, "Learning Textual Graph Patterns to Detect Causal Event Relations," in the Twenty-Third International Florida Artificial Intelligence Research Society Conference (FLAIRS 2010) Learning, pp. 265-270, 2010.

[20] C. Khoo, S. Chan, Y. Niu, and A. Ang, "A method for extracting causal knowledge from textual databases," Singapore J. Libr. Inf. Manag., vol. 28, pp. 48-63, 1999.

[21] C. Khoo, S. Chan, and Y. Niu, "Extracting causal knowledge from a medical database using graphical patterns," Proc. 38th Annu. Meet. Assoc. Comput. Linguist., pp. 336-343, 2000.

[22] C. Khoo, "Automatic Extraction of Cause-Effect Information From Newspaper Text Without Knowledge-Based Inferencing," Literary \& Linguistic Computing, vol. 13, no. 4, pp. 177-186, 1998.

[23] W. Park and M. Abraham, "Acquisition of Causal Information From Medical Documents in French for Experts," in 23rd Annual EMBS international Conference, pp. 3848-3851, 2001.

[24] M. Riaz and R. Girju, "In-depth Exploitation of Noun and Verb Semantics to Identify Causation in Verb-Noun Pairs," in The 15th Annual Meeting of the Special Interest Group on Discourse and Dialogue, pp. 161-170, 2014.

[25] T. N. De Silva, X. Zhibo, Z. Rui, and M. Kezhi, "Causal Relation Identification Using Convolutional Neural Networks and Knowledge Based Features," International Journal of Computer and Systems Engineering, vol. 11, no. 6, pp. 691-696, 2017.

[26] "Desa Sigedong Temanggung KLB Diare, 1 Korban Meninggal Dunia," okezone.com, 2017. [Online]. Available: https://lifestyle.okezone.com/read/2017/08/09/481/1752519/desa-sigedong-temanggung-klb-diare-1-korbanmeninggal-dunia [Accessed 12 Feb. 2018]. 